\title{
APPLICATION OF EXTENDSIM FOR IMPROVEMENT OF PRODUCTION LOGISTICS' EFFICIENCY
}

\author{
Straka, M. ; Malindzakova, M. ; Trebuna, P.**; Rosova, A. ; Pekarcikova, M. ${ }^{* *} \&$ Fill, M.* \\ * Institute of Logistics, BERG Faculty, Technical University of Kosice, Park Komenskeho 14, 04384 \\ Kosice, Slovakia \\ ** Institute of Technologies and Management, Department of Industrial Engineering and Management, \\ Faculty of Mechanical Engineering, Technical University of Kosice, Bozeny Nemcovej 32, 04001 \\ Kosice, Slovakia \\ E-Mail: martin.straka@tuke.sk, marcela.malindzakova@tuke.sk, peter.trebuna@tuke.sk, \\ andrea.rosova@tuke.sk,miriam.pekarcikova@tuke.sk,maros.fill@tuke.sk
}

\begin{abstract}
The article deals with the use of computer simulation approach in order to streamline production logistics within a specific production company. The computer simulation from its very beginnings has undergone a long and significant evolution. The current possibilities of computer simulation approach enable to mimic the real processes of production logistic activities as well as of the actual production. This article is focused on the question, how to effectively utilise the available tools of computer simulation approach to analyse and streamline a particular simulation system. Therefore also the presented solution is the actual description of a practical application of a computer simulation approach used for the needs of one specific production company within one specific industry area. The intention is to showcase the practical aspects of simulation modelling, in this case utilising the EXTENDSIM simulation system. The simulation approach will be used for the needs of a production company, that produces car components and accessories made of wood for the automotive industry. (Received in November 2016, accepted in January 2017. This paper was with the authors 1 month for 2 revisions.)
\end{abstract}

Key Words: Computer Simulation, Production Logistics, Production System, Processes, EXTENDSIM

\section{INTRODUCTION}

The use of simulation modelling as a scientific method in research and in practice is very widespread. The benefits that stem from the use of a simulation modelling approach include financial, time, material and energy savings as well as the streamlining of activities in practice. Simulation is therefore widely applied in various industries and areas, such as education, health, information technology and robotics, economics, business, logistics and transport services.

In the same way as the company gradually goes through different stages of development, so can the means of simulation modelling adapt to the requirements of any given development stage. Similarly, as a house is gradually being constructed so the simulation models can be built from specific blocks, objects, components and other tools within the simulation systems. Understanding of simulation principles and knowledge of simulation building blocks, their properties and their usage is an essential key for the creation of any simulation model, especially if it is supposed to match the real system and the vision of the model creator [1]. One common feature in the development of a simulation model is the same for all modelling methods and that is the logical follow-up. This feature is common not only for simulation modelling by statements, but also for simulation modelling by building blocks [2].

Continuous demographic changes within society increase the demand for more efficient processes, putting a pressure on all production and non-production companies that for their growth need to employs different approaches for effective team building, for implementation of automation and robotics, and for effective management. As the development and 
implementation of production logistics became widespread, the companies found that in this area is possible to save up to $40 \%$ of costs only by efficient management and streamlining of production flows without the actual need to purchase new equipment [3]. The development of advanced simulation systems opened new possibilities and significantly supported the trend to streamline production activities, and thus reduce costs and increase [4].

An essential preliminary step during the creation of a simulation model is a detailed identification and analysis of all specific activities within the company [5]. The next step is the creation of a formalized scheme containing selected system parameters. Following step is the actual creation of a simulation model, followed by debugging, verification and subsequent research with a specific aim to streamline production $[6,7]$.

\section{LITERATURE REVIEW}

Logistics as a scientific discipline was first defined back in the 50s. Subsequently there was the development of the MRP I - Material Requirements Planning system. Later in the 60s the MRP II - Manufacturing Resources Planning system was created, where the original MRP was supplemented by the algorithms for capacity calculations [8]. In the 70 years the method called Just-in-time was discovered for the first time. During the 80 s the advancements in computer technology helped to accelerate the information flows. Later, the fully integrated logistics systems gradually started to emerge, which resulted in cost savings and by gradual replacement of manual work by mechanisation [9]. The area of logistics covers a variety of technical means such as elements of classical transport, elements of production facilities, robots [10] and recently also modern drones.

The importance of logistics is growing along with increasing globalization. All companies are exposed to strong competitive pressure, and in this situation logistics plays a strategic role. Logistics helps to reduce the costs, to achieve higher profits and to improve customer service. The efficiency logistics improves along with the development of information technology [11].

Simulation is however not a tool for getting the optimal solution, but it is a tool that allows you to test different decision outputs on a simulation model. Such model allows performing a variety of experiments to evaluate, analyse, and to determine solution parameters that can be subsequently used for the real system. The risk factors can be examined and determined in advance, by "replaying" the simulation model run whilst observing the performance and behaviour of the system, then after applying the required changes, examine the future behaviour of the system, where any potential problems and bottlenecks can be removed in advance. Animations of manufacturing processes provide better clarity and insight into production processes, without running the risk of harming the actual real life production system by repeated experimentation. Such understanding and knowledge can be then used to avoid mistakes and deficiencies in order to prevent any potential failures $[12,13]$.

The simulation model created within the EXTENDSIM simulation program is defined by a specific sequence of modelling blocks connected by lines representing the processing flow directions. The block position, the icon and name, the connector blocks, the links as well as the user interface dialogues with operands and flows are the main properties of individual blocks. The blocks themselves represent individual processes or subsystems thus creating the actual representation of the real life system under examination. The icons and blocks are the graphic representation of each facility or of an operation, with exact unique name that describes their defined function and the primary purpose of the given particular block within the model. The block labelled "create" represents the generation of input requirements while the model block labelled "queue" defines the creation of a series of demands, with the input to the queue and the subsequent output. The block labelled "exit" represents the simulation 
model output. The blocks connectors enable connecting each blocks with one another in accordance with the rule that one connector can only connect the input with one output slot. The connectors between two different blocks form a logical sequence of blocks, which reflects the real system and forms the basis for the production flows. The connected blocks represent the real sequence of units and facilities within the examined system. User interface windows and operands enable to specify items characteristic and block properties for any given block. This is done by opening a user interface window, when the parameters and properties of each block can be displayed and specified for each modelling block $[1,6]$.

The simulation outputs are the most valuable for the production companies during the initial stages of a business development or in the initial phase of a new production launch. However simulation approach and methods can be successfully utilised also in the following situations:

- Reorganization of the organizational structure.

- Reengineering of technology and all business processes.

- Restructuring of the production program.

- There is a need to dramatically improve manufacturing and business processes.

The following section wishes to provide a basic set of terms and definition used within the context of this article. A model represents a simplified process or a facility. It can be based on any real facility or activity within any given process. Then by simulation modelling we understand the simulation model design and creation. On the other hand, by simulation we understand the actual experimentation performed by running an already created simulation model. Under logistics we understand a system that manages, provides and facilitates logistic flows and chains, which consist of elements such as facilities, machinery, equipment, people, activities, processes, products, information, and money that together generate production flows [14]. Surrounding environment of a logistics system consists of other logistics systems, since each object within a process can be perceived as a logistics system.

\section{RESEARCHED COMPANY}

The investigated company is focused on timber processing of production of wooden products such as car interior parts for the automotive industry and the production of waste pallets. The Management and the production of the company is centralized, which helps to maintain the accessibility to important information from the surrounding markets as well as from the internal structures of the company.

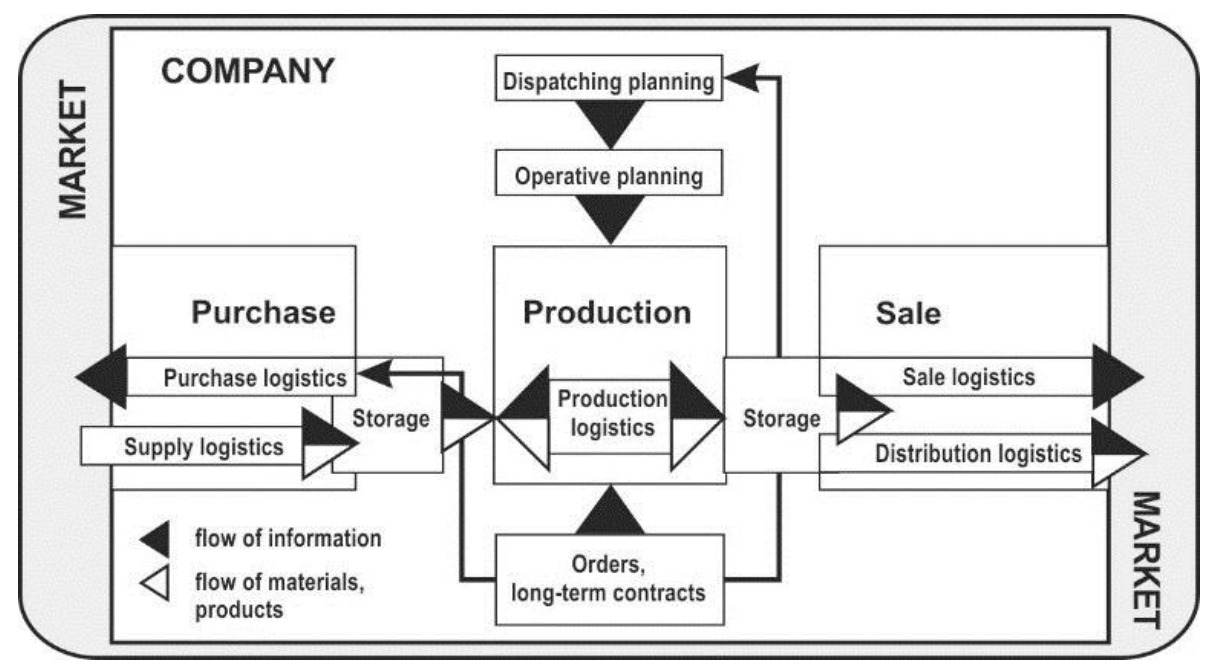

Figure 1: Model of the company logistics. 
Purchase - the company is constantly looking for new opportunities in the local area to obtain the best quality timber material in order to make the most effective use of the available resources. Therefore, the purchase of timber material is the most important phase for the company within the model of company logistics (see Fig. 1). The described company has its headquarters office in Slovakia near the technology park Kechnec where several other companies that produce car components for the automotive industry are located. The company utilises several suppliers, not only in Slovakia but also in the neighbouring Hungary. Among those suppliers are mainly companies engaged in mining and in the timber material harvest, but there are also state owned companies. When purchasing the timber material, the representative from the purchasing department must make the decision on the selection and on the quality of purchased timber material. The supply of raw timber material from the forest to the storage space is provided by an external company, which has long been cooperating with the company. In terms of company supplying timber material, this can be regarded as an outsourcing. The storage of raw material in a certain amounts is necessary to ensure the smooth run of the production process. The storage place, which can be regarded as the input point of materials for the system, should contain at least one-week worth of timber material amount, which represents approx. $60-70 \mathrm{~m}^{3}$ of timber material. The entire production process of this particular company is dependent on the ability of the operators to process the purchased timber material in order to achieve the best possible yield whilst maintaining the least possible amount of waste. A common situation that occurs is the decision to change the daily tasks within the production. All such decisions depend on the incoming orders and their execution times and also on the quality of the purchased material. Company sale of products is influenced the most by factors that can potentially cause certain level of problems in one of the production areas. Another influential factor is the economic situation on the market. Currently, the company tries to run production only based on pre-orders to minimize production for warehouse. Such a lean production is based on the idea of shortening the time between the customer and the supplier, eliminating the potential waste in the supply chain, which is also what the investigated company is trying to achieve [15]. The distribution, the materials handling and the products transport, the company realizes by its own means. The company over the years acquired vehicles, loaders and trucks, which are necessary for its production activities. In this aspect the company is self-sufficient and more independent, in contrast to company's competition. One of the long-term efforts of the company is also to increase the flexibility in relation to requests of company customers.

\section{USING THE EXTENDSIM SIMULATION SYSTEM FOR THE NEEDS OF THE PRODUCTION LOGISTICS}

As next step for the above described company a comprehensive simulation model of all the activities within the timber material processing was prepared, which required a thorough analysis and compliance with the following steps:

- the creation of a formalized scheme with ties to the various levels of production and equipment,

- description of production units, the sequence of operations and the data collection of production parameters such as idle times, frequencies, cadence, volumes as well as flow pooling,

- the creation of block diagram as a basis for simulation model,

- the creation of simulation model, simulation runs and research with an aim to streamline the production,

- the improvement of efficiency of production logistics by EXTENDSIM simulation system. 


\subsection{The creation of the formalized scheme}

To make the computer simulation model it is appropriate first step to create a formalized scheme that represents the exact sequence of production operations, interconnecting facilities with the technical resources of the company. This step also involves retrieving the information about the parameters of the material flows in terms of volume distributions. Such a formalized scheme then represents the overall system with its features and links. In this particular case the system consists of individual elements represented by operations with timber material. Between operations are links formed by elements of flow management of semi-finished products and of timber waste. A formalized structure (see Fig. 2) is a very important basis for the creation of an actual simulation model. The understanding of system operations, its parameters and constraints is important for the subsequent examination of the production system and its optimal setting with the intention to maximise the utilisation of production capacities [16, 17]. During the subsequent simulation modelling the individual parts of a formalized scheme will be replaced by a respective block of specific simulation software. The available time for production is crucial for control and adjustment of production $[18,19]$.

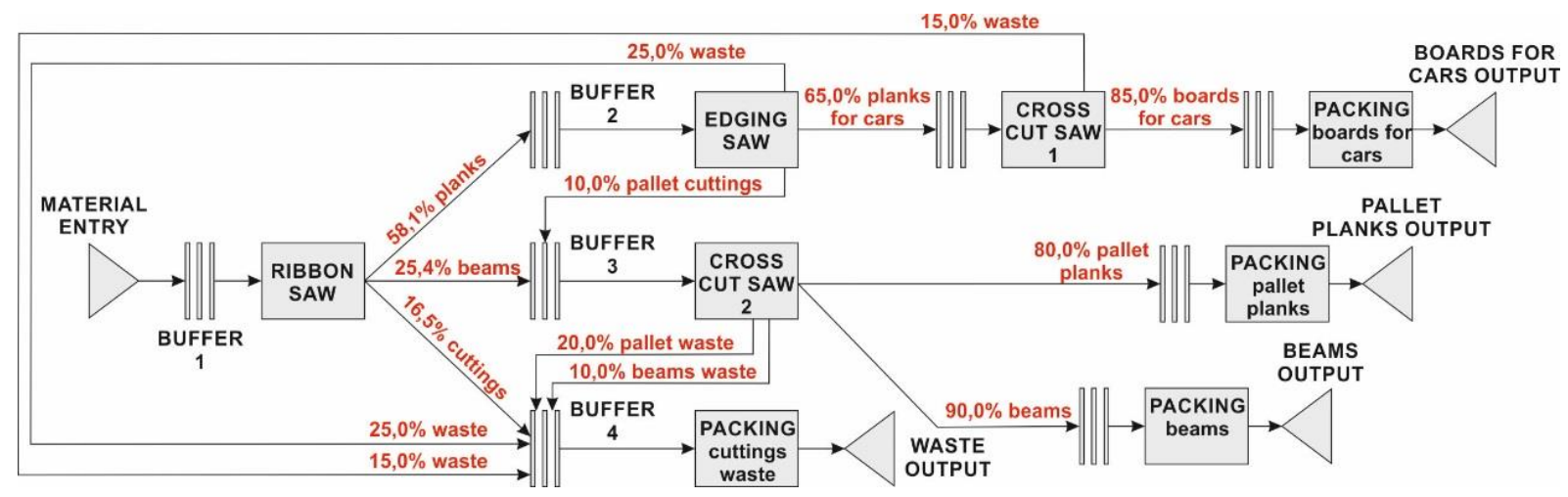

Figure 2: The formalized scheme for production of wooden components for car interiors.

\subsection{The description of production units}

The company is equipped with a technology that consists of a number of special equipment to process raw timber material. In this system there are devices such as ribbon saw, edging saw, two cross cut saws and two workplaces for packing of products and of waste. The input of timber material for the needs of production is dependent on the suppliers and on the demand for the quantities of produced wooden components. The input, which in this case is the supply of material, reflects an interval value from 10 to 20 minutes, which represents the frequency of how often another piece of input material (logs of timber) enters the production process. Ribbon saw is the first device in the production process where the logs of raw timber are processed, cut into smaller sections, beams and slabs. The processing time depends on the diameter of logs and on the timber properties. The cutting of a single piece of log takes, depending on the hardness and on the size of the timber material between 12 to 30 minutes.

The output at stage is represented by regular size boards, which constitute $58.1 \%$ of the production volume, palette planks constitute $25.4 \%$ of the production volume, and cuttings constitute $16.5 \%$ of the total production. The edging saw processes the material coming from the ribbon saw. Edging saw is used to vertically cut unprocessed timber (boards, palette planks) by sawing blade. Processing time of one board takes 13-20 minutes.

The output material of edging saws are cuttings for wooden interior accessories for cars, which represent $65 \%$ of the production volume, pallet cuttings represents $10 \%$ of production and other waste comprises $25 \%$ of production. 
The cross cut saw number 1 is designed to cut boards coming from edging saw to the desired length. The output is the finished material e.g. boards for wooden interior accessories for cars which represent $85 \%$ of the overall volume of sawn boards. Another $15 \%$ are waste. Processing time is 32-45 minutes. The cross cut saw number 2 handles incoming material from the ribbon saw and from the edging saw. From the ribbon saw, enters $25.4 \%$ of the material (beams) which for the machine represents a $100 \%$ of input and the output is represented by $90 \%$ of the finished material (beams). From the edging saws enters $10 \%$ of the material (pallet planks) the cross cut saw number 2 which is for the machine represents a $100 \%$ of input and the output is represented by $80 \%$ of already finished material. Processing time is $13-17$ minutes.

\subsection{The creation of block diagram as a basis model of the concrete production}

To create the block diagram (see Fig. 3), as a basis for the actual simulation model, it is important to prepare the data and the information that are important for the setting of individual blocks within the simulation model. From the statistical data obtained from observation and measurement in the field as well as from the technical documentation data, it appears that the input of the timber material into system occurs each 10-20 minutes, when another piece of timber material enters the system. In the simulation model this is modelled by the entry block "create" with normal distribution setting of $15 \pm 5$ minutes. Just before the first production facility which is the ribbon saw, there is an unprocessed timber storage, which balances the cadence delays within production and the capacity of the control unit. In the simulation model this is represented by block "queue" with the setting "first in first out $(F I F O)$ ". As next there is a ribbon saw type of device, where the processing of a single piece of timber ranges from 12 to 30 minutes. In the simulation model this delay is modelled by a triangular distribution with delay parameters set to a range from 12 minutes to 30 minutes and most frequent value of 19 minutes, for processing of one piece of timber. After the raw timber logs are cut, the material is separated into boards, pallet planks and beams. The rest of the timber cuttings is considered waste and is sent into the incinerator. Separating the material is modelled in the simulation by the block "select item out", where $58.1 \%$ of the total mass are the boards for the production of cuttings, which are the semi-finished car components, $25.4 \%$ of the total mass are the blocks and planks for pallets production and $16.5 \%$ of the total mass is the timber waste.

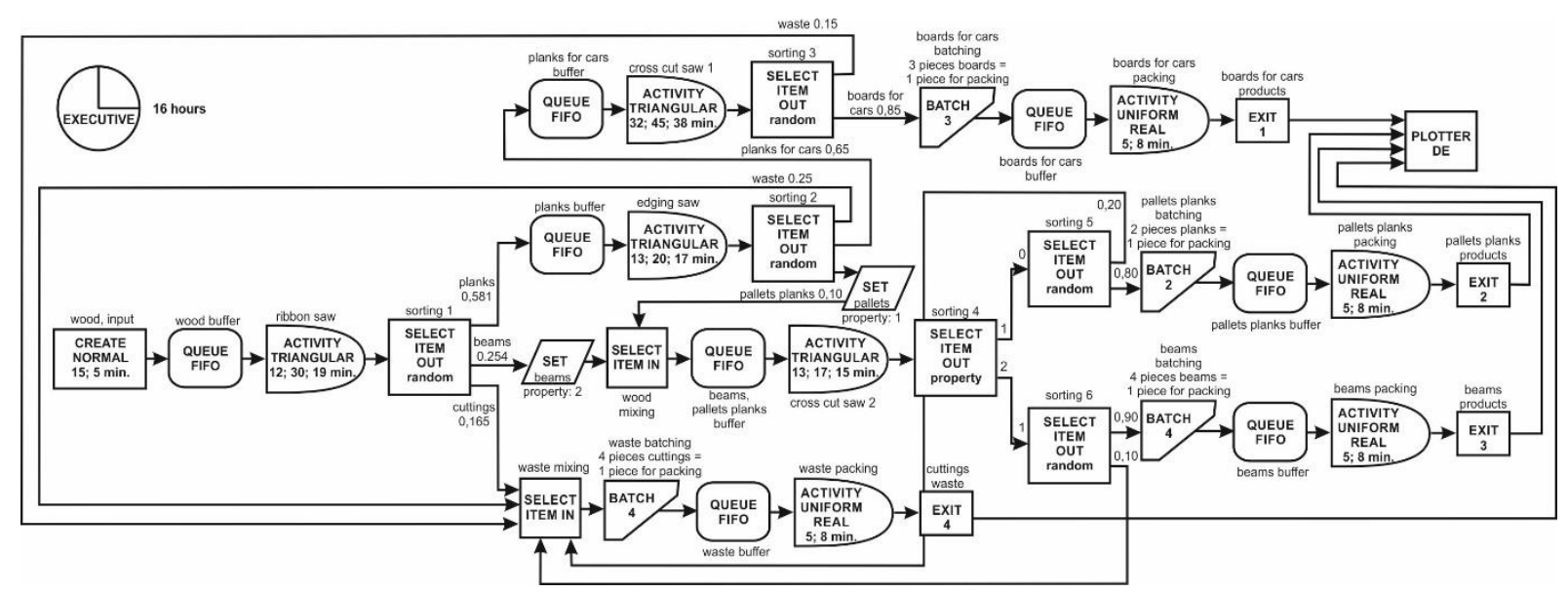

Figure 3: Block diagram of the production of timber cuttings for car interior accessories.

Production of cuttings for the needs of the automotive industry continues by processing at the edging saw, which is represented in the simulation model by the block "activity". The delay on the device is represented by a triangular distribution with parameters delays set to a 
range from 13 minutes to $20 \mathrm{~min}$ and the most frequent value set to 17 minutes, for the processing of one piece of timber. Before the edging saw there is a storage, which is represented by the block "queue" with the FIFO setting. After the processing at at the edging saw, follows the material separation, sorting the material into category which meets the quality specifications for the timber material for car interiors $(65 \%)$, into the material category that does not meet the quality requirements for car industry but is suitable for production of pallets $(10 \%)$ and the rest $(25 \%)$ which again is considered the timber waste. This sorting of timber materials based on quality into categories is represented by the simulation block "select item out". The prepared cuttings for cars interior accessories are then cut into desired dimensions at the cross cutting saw. Cross cut saw is represented in the simulation model block "activity".

The delay on this device is represented by triangular distribution with parameters delays set to a range from 32 minutes to 45 minutes and the most frequent value set to 38 minutes for the processing of one single piece of timber. Before the cross cut saw there is a buffer, which is represented by the block "queue" with the FIFO setting. After cutting the material into the required dimensions, there is as subsequent sorting into semi-finished products that are suitable for shipment to customers $(85 \%)$ and the rest, which represents again the timber waste $(15 \%)$. The sorting of material after the cutting operation on the cross cut saw is represented by block "select item out".

The semi-finished products that later will be further processed, furnished and polished are packed and sealed into boxes and sent for export. They are packed by three pieces for one package. This operation is represented in the simulation model by a set of blocks "batch queue - activity". In the simulation block "batch" represents the accumulation of three semifinished products. Block "queue" represents the buffer for products ready for packing and set of blocks "activity" represents the actual packing. The delay for packing is represented by the uniform distribution of real parameters for delay ranging from 5 minutes to 8 minutes per packing and for the preparation of boxes with products. The shipment of products is represented by the simulation block "exit".

The beams, planks and other timber elements for the production pallets production needs to be cut into required dimensions at the cross cut saw 2 . To identify this category of materials within the simulation model such material needs to be marked. Such marking of elements takes place in the simulation block "set" with the character designation "property" marked with values of 1 or 2 . A value of 1 represents items of timber components for production of pallets and the value of 2 represents the wooden beams. Joining of two flows of goods occurs within the block "select item in".

Subsequent cutting occurs at the cross cut saw 2. This operation is represented by the block "activity" with triangular distribution with duration parameters set to a range from 13 minutes to 17 minutes and the most frequent value set to 15 minutes, per one piece of timber. After cutting the timber elements are packed and shipped. In the simulation model it is first necessary to identify what type of timber product left the facility. Identification is carried out in the blocks "select Item out" with the marking using "property".

Products of type 1 are transported via the connector with the index 0 . The block "select item out" is used to sorts $80 \%$ as finished timber elements for pallets production and $20 \%$ as timber waste. Product of type 2 are transported via the connector with an index of 1 , and the block "select item out" is used to separate $90 \%$ of finished timber product as beams construction for construction purposes from $10 \%$ of timber waste. Then follow the activities of product packing and of shipment to customers. Packing in the simulation model is represented by the set of blocks "batch-queue - activity", in the same way as the packing of products for automotive industry. The shipment of products and output from the monitored system are represented by the block "exit". 
The resulting timber waste is packed into sacks and exported to customers that are then using it to produce wood pellets for heating. The process of accumulating and waste packing for shipment is represented by the set of blocks "select item in - batch - queue - activity". The packaged timber waste then finally leaves the simulation model through the block "exit".

The prepared block diagram model of timber processing and production represents the inactive part of the actual computer simulation model. Then follows the application of a block diagram for a particular simulation system, which is the part where the inactive block scheme changes into an active computer simulation model. The acquired data and information from this active computer simulation model represent the actual current state of production activities for timber cuttings within the investigated company. By adjusting parameters and by examining the resulting influences and impacts on the simulation model, one can identify potential bottlenecks and define recommendations and improvements for the operation of this particular production. Computer simulation allows without direct intervention into the system to improve the economics of the company considering the technological aspects of the production as well as total logistics of a company. All the resulting recommendations contain also certain level of defined environmental and social aspects. Each block within the simulation model has its own purpose and justification. Of course, not all operations can be modelled by using one single simulation block; one has to often use a combination of several blocks in the sequence in order to model the corresponding real system feature within the production process. Not less important part the simulation modelling is the proper and consistent parameter setting of the simulation model, as indicated from the analysis of the formalized and from the block diagram.

\subsection{The creation of simulation model within the EXTENDSIM system}

Entry of timber into the company and storage of logs is represented by the blocks "create" and "queue" (see Fig. 4).

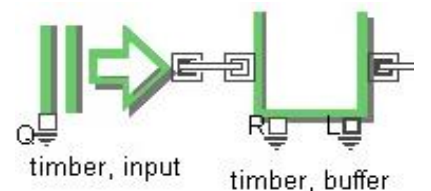

Figure 4: Blocks "create" and "queue" which represent the entry of timber material into the company and the storage of logs.

In the block "create" it is necessary to set the parameters for the entry of timber material into the enterprise. The timber material delivered into the company on regular basis and the simulation system input are configured based on normal distribution with a mean frequency for entry set to 15 minutes and standard deviation set to 5 minutes (see Fig. 5).

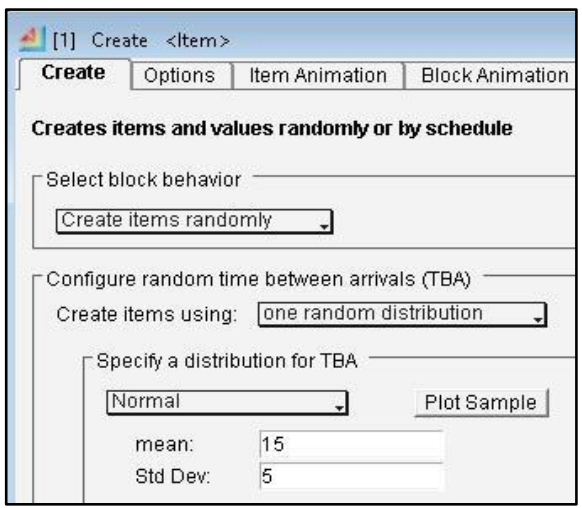

Figure 5: Dialogue block "create" and its settings for the requirements of the simulation model. 
In regard to the actual implementation of the timber processing and following reprocessing into semi product such as boards, planks and beams based on customer specifications are modelled using blocks "queue", "activity" and "select item out" (see Fig. 6). These three interconnected blocks represents a buffer for timber just before the production facility, the actual production facility and the third block represents the sorting of various types of timber products resulting from processing at the particular facility as well as the remaining timber waste from the production from this particular processing unit. This particular set of blocks can be then used for the ribbon saw (see Fig. 6), the edging saw (see Fig. 7) and the cross cut saws (see Fig. 8).

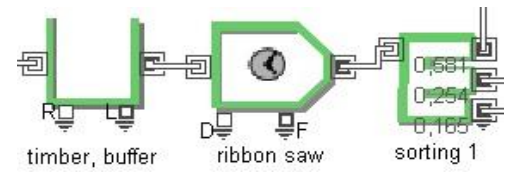

Figure 6: Blocks "queue", "activity" and "select item out" in this figure represent the buffer, production facility and sorting within the ribbon saw facility.

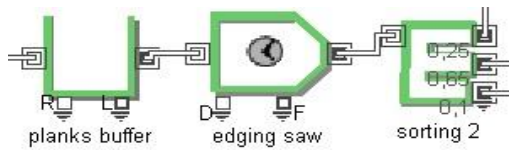

Figure 7: Blocks "queue", "activity" and "select item out" in this figure represent the buffer, production facility and sorting within the edging saw facility.

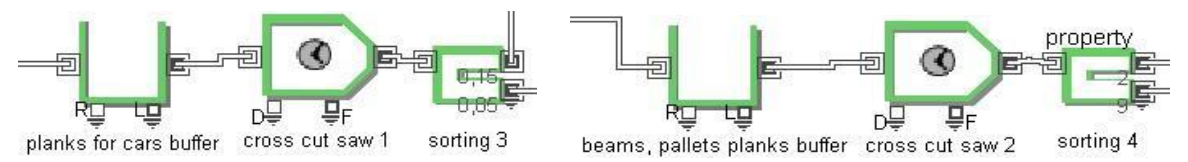

Figure 8: Blocks "queue", "activity" and "select item out" in this figure represent the buffer, production facility and sorting within the cross cut saws facilities.

Not less important is the preparation of products for packing and shipment (see Fig. 9). These activities are represented in the simulation model by the block "batch", "queue", "activity" and "exit".

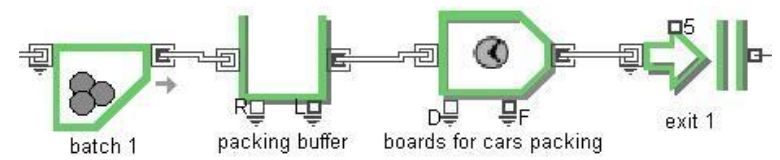

Figure 9: Blocks "batch", "queue", "activity" and "exit", accumulation, buffer, production facility, and exit for all workplaces.

By combining the above described simulation model elements, a number of selected production processes were modelled that represent the actual real life production systems within the investigated company (see Fig. 10).

\subsection{Improvement of efficiency of production logistics by EXTENDSIM}

After setting the simulation model, as next follows the testing and research stage in order to identify potential bottlenecks and to streamline the production logistics of timber production. The advantage of computer simulation is the fact that it is possible to examine variety production parameter settings that would be either costly or unsafe to test in real environment of an industrial company. Within this particular scenario, the simulation has been used to examine the production within two shifts cycle, where one shift lasts eight hours for a total of 16 hours. The results thus reflect the current state of the company. As the simulation results indicate, the bottleneck is actually the very first production facility or workplace, namely the 
ribbon saw (see Fig. 11). The given state is derived from the simulation analysis and has been verified by the leading technology manager from the company. The findings indicate that this facility is not sufficiently efficient to process the timber material entering the production process, which results in accumulation of unprocessed material. This however over time leads to gradual degradation of quality and thus to unnecessary waste of company resources.

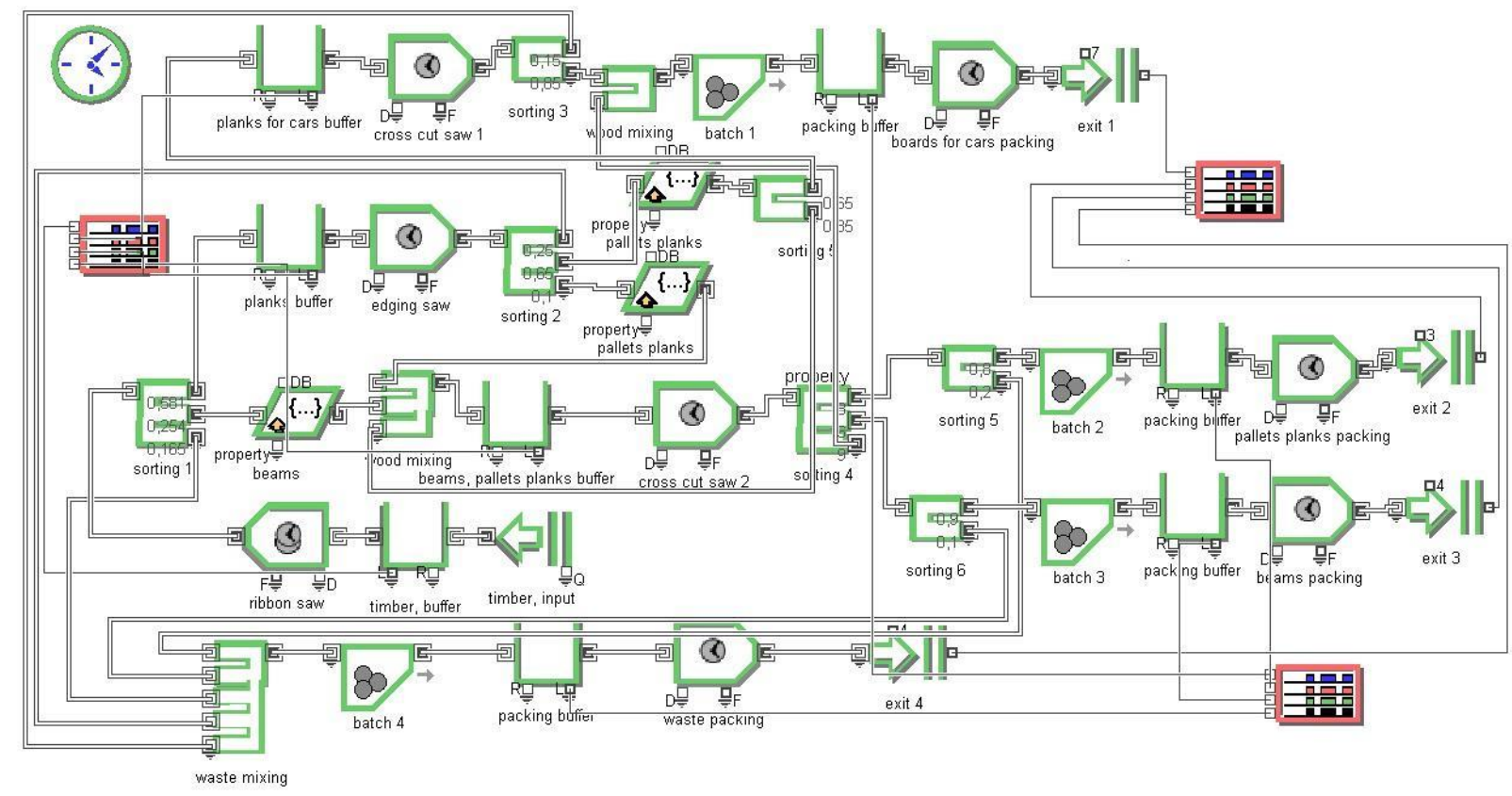

Figure 10: The simulation model of the timber processing and production facilities within the investigated company.

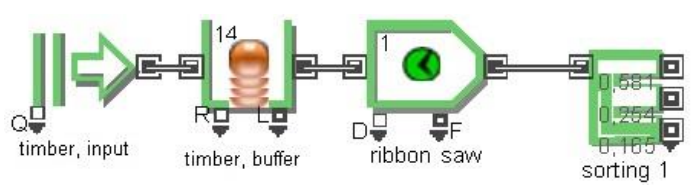

Figure 11: Workplace "ribbon saw", the creation of unprocessed requests within the queue in block "queue - wood, buffer".

The utilisation capacity of the "ribbon saw" facility is 1.0 , which represents $100 \%$ (see Fig. 12), which means that this particular facility can process approximately 47 pieces of timber logs within the designated time limit. However, within the same time limit at current logistics setting approximately 68 timber $\operatorname{logs}$ can be delivered into the system. This mismatch between the system input frequency and the processing times at the first processing facility inevitably leads to accumulation of material. The utilisation of other facilities, namely the "edging saw" and the "cross cut saws" ranges from 0.28 to 0.77 , which represents range from 28 to $77 \%$ of maximum production capacity. This leads to undesirable idle times and downtimes.

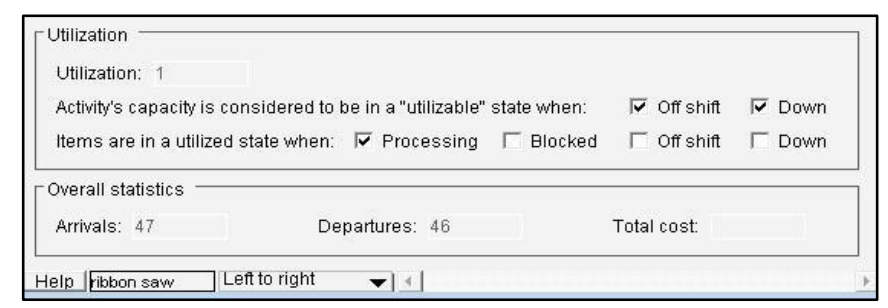

Figure 12: The utilisation capacity of the production facility "ribbon saw" within the designated time limit for the production of timber cuttings. 
Within the simulated time period, five packs of special wooden components for the automotive industry were produced, two packs of timber material for the production of pallets, two packs of timber beams three packs of timber waste (see Table I a).

Table I: The outputs from the simulation model for the observed production system during the simulated time period.

a)

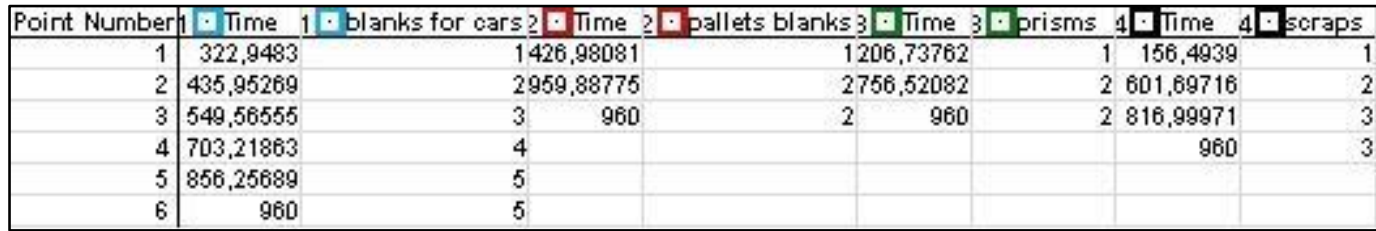

b)

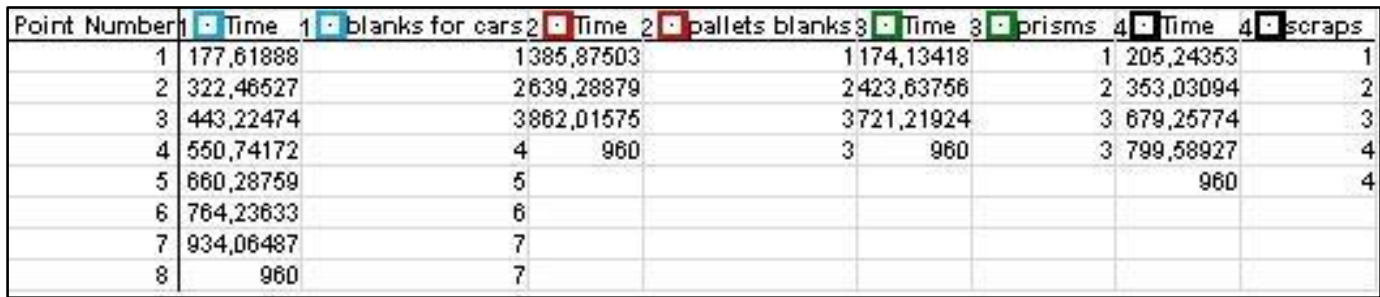

The simulation output data show that a part of the production system is overloaded, where on the other hand other parts of the system have substantial reserves. In order to streamline the production, there are two possibilities:

1) For the production facility "ribbon saw" implement a three-shift cycle (two additional workers are needed to operate the facility during the third shift), thereby produce in advance enough timber components for the rest of the workplaces that would still operate in the original mode. By implementing this approach all incoming timber material can be processed without delays, which would make room for further development of technology. This adjustment would increase the production capacity by about 35-40\%, without the need for costly investments (see Table I b). The production capacity of workplace "cross cut saw 1" would increase to $91 \%$ (see Fig. 13 a). However the "cross cut saw 2" facility even with this change is still utilised only by $28 \%$ (see Fig. $13 \mathrm{~b}$ ). This means that the production throughput must be allocated equally to both facilities, which again can be achieved without any need for expensive equipment for size adjustment or cutting of timber material. By introducing this material flow modification, the production capacity at both facilities has been stabilised at about 55-60 \%. It also creates a reserve for possible further development of the company. The "edging saw" facility after the implementation of the above changes is running at around $70 \%$ of its production capacity. That represents a sufficient margin to meet the management and production development goals.

a)

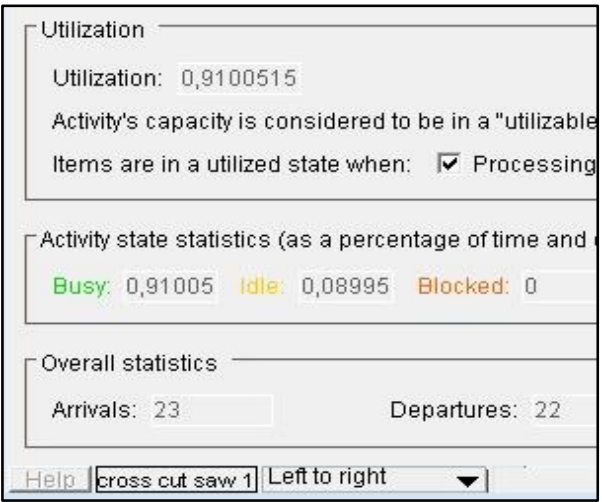

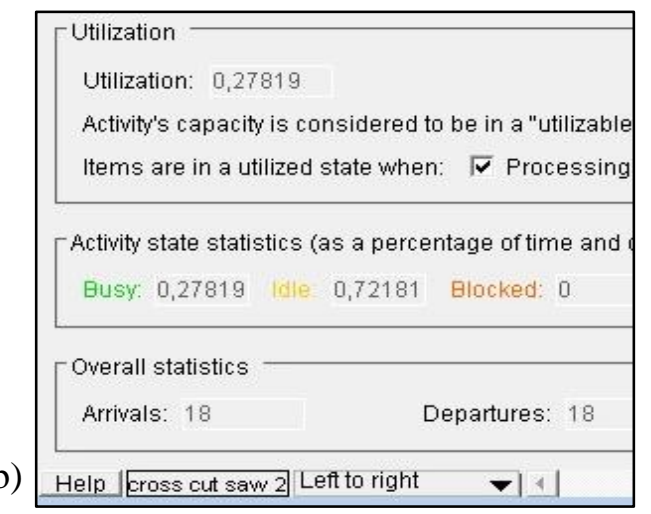

b)

Figure 13: The utilisation capacity of the production facility „cross cut saw" within the designated time limit for the production of timber cuttings. 
2) Strengthen the workplace "ribbon saw" by purchasing another device, which however requires considerable investment (price of a ribbon saw stands at about 26,000 Euros, plus there is also need for additional staff to operate the new facility). By implementing this production adjustment, just about the same amount of timber elements would be produced as in the previous adjustment of work time schedule (see Table I b). Other facilities such as the "edging saw" and the "cross cut saws" still maintain similar production capacities as in the previous adjustment scenario. The packing workstations are utilised only to $4 \%$, which suggests that merging of workplaces is recommended. It would be appropriate to utilise the available workers as the crew for the third shift at the "ribbon saw" production facility.

\section{CONCLUSION AND OPEN QUESTIONS}

Simulation systems like Witness, Simul8, EXTENDSIM, Tecnomatix, GPSS, Siman, and others, allow users to create simulation models of complex production systems. Many simulation tools even combine the capabilities to model so called discrete and continuous simulation. By today standards, several simulation systems also provide the capabilities to display and to present the actual simulation model and often also the simulation run either using $2 \mathrm{D}$ or $3 \mathrm{D}$ overview to monitor functional aspects of the simulation.

The above described case study, where the simulation modelling has been successfully implemented for the needs of a company producing wooden components and accessories for car interiors, demonstrates the capabilities of simulation modelling and the advantages of such approach for the advancement of science as well as for the application in solving the everyday problems in general practice. The recommendations for the above described company, supported by the simulation results were subsequently applied in practice. The practice then verified the simulation outputs from the EXTENDSIM simulation system and confirmed the validation of proposed recommendations. In terms of the link to production logistics of the company, the simulation results have shown that in order to solve the production problems it is not necessary to purchase expensive equipment. Quite the opposite, there are possibilities to increase utilization capacity, gain time reserve and solve the bottlenecks whilst still maintaining low production costs. Only after spending the available time reserves and available capacities of production facilities, only then it would be necessary for the company to realize the purchase of new technology equipment. Of course, by then it will be also needed to take into consideration the qualitative and moral wear of the production facilities. Thanks to the application of EXTENDSIM simulation system, the production capacities have been increased in the case study company, which demonstrates the importance of computer simulation to solve this type of tasks. The assignment goal that was defined in the introduction to this article has been achieved.

In terms of further research, the following questions still remains open for consideration:

- When is the right time, or where is the "tipping point" for the purchase of a new technology for the needs of this particular production? When the time reserves and the capacity of production facilities run out, by then it may be already too late in comparison to competition; on the other hand, if this new equipment is purchased before the "tipping point" the company unnecessarily incurs no small costs for such purchase.

- How to implement a change in the production technology? Is such change supposed to be realised in gradual steps? Can the changes occur concurrently or sequentially?

In general it can be stated that the use of simulation systems for troubleshooting of problems within production logistics or in general logistics areas is the right way approach as demonstrated by the successful case study presented in this article. 


\section{ACKNOWLEDGEMENT}

This work was supported by the Slovak Research and Development Grant Agency, VEGA grant number 1/0708/16.

\section{REFERENCES}

[1] Straka, M.; Malindzakova, M.; Rosova, A.; Trebuna, P. (2016). The simulation model of the material flow of municipal waste recovery, Przemysl Chemiczny, Vol. 95, No. 4, 773-777, doi: $10.15199 / 62.2016 .4 .12$

[2] Malindzak, D. (2010). Models and simulation in logistics, Acta Montanistica Slovaca, Vol. 15, Special Issue No. 1, 1-3

[3] Malindzak, D.; Spisak, J.; Drabik, L.; Gross, I.; Grossova, S.; Krawczyk, S.; Lenort, R.; Nemec, F.; Rosova, A.; Straka, M.; Strakos, V. (2007). Theory of Logistics, $1^{\text {st }}$ edition, Karnat, Kosice

[4] Bohacs, G.; Semrau, K. F. (2012). Automatic visual data collection in material flow systems and the application to simulation models, Logistics Journal, Vol. 2012, No. 1, 1-7, doi:10.2195/lj_NotRev bohacs de 201201

[5] Seebacher, G.; Winkler, H.; Oberegger, B. (2015). In-plant logistics efficiency valuation using discrete event simulation, International Journal of Simulation Modelling, Vol. 14, No. 1, 60-70, doi:10.2507/IJSIMM14(1)6.289

[6] Straka, M. (2007). Discrete and continuous simulation in simulation language Extend, $1^{\text {st }}$ edition, Edičné stredisko/AMS, Košice

[7] Pekarcikova, M.; Trebuna, P.; Markovic, J. (2015). Simulation as part of industrial practice, Acta Logistica, Vol. 2, No. 2, 5-8

[8] Toomey, J. W. (1996). MRP II: Planning for Manufacturing Excellence, Chapman \& Hall, New York

[9] Ohno, T. (1998). Toyota Production System - Beyond Large-Scale Production, Productivity Press, Portland

[10] Karabegovic, I.; Karabegovic, E.; Mahmic, M.; Husak, E. (2015). The application of service robots for logistics in manufacturing processes, Advances in Production Engineering \& Management, Vol. 10, No. 4, 185-194, doi:10.14743/apem2015.4.201

[11] Groover, M. P. (2007). Automation, Production Systems and Computer-Integrated Manufacturing, $3^{\text {rd }}$ edition, Prentice Hall, Upper Saddle River

[12] Stangova, A. (2014). Programming of methods for the needs of logistics distribution solving problems, Acta Logistica, Vol. 1, No. 2, 15-18

[13] Gyimesi, A.; Bohacs, G. (2015). Developing a new logistics based model and pilot system for construction, Periodica Polytechnica Transportation Engineering, Vol. 43, No. 4, 211-217, doi:10.3311/PPtr.7845

[14] Winkler, H.; Kuss, C.; Wurzer, T.; Seebacher, G.; Winkler, S. (2014). Supply Chain Improvement Projekte und Systeme, Logos Verlag, Berlin

[15] Jia, Z.; Lu, X.; Wang, W.; Jia, D.; Wang, L. (2011). Design and implementation of lean facility layout system of a production line, International Journal of Industrial Engineering: Theory, Applications and Practice, Vol. 18, No. 5, 260-269

[16] Benedito, E.; Corominas, A. (2010). Optimal manufacturing and remanufacturing capacities of systems with reverse logistics and deterministic uniform demand, Journal of Industrial Engineering and Management, Vol. 3, No. 1, 33-53, doi:10.3926/jiem.2010.v3n1.p33-53

[17] Kaban, A. K.; Othman, Z.; Rohmah, D. S. (2012). Comparison of dispatching rules in job-shop scheduling problem using simulation: a case study, International Journal of Simulation Modelling, Vol. 11, No. 3, 129-140, doi:10.2507/IJSIMM11(3)2.201

[18] Gracanin, D.; Lalic, B.; Beker, I.; Lalic, D.; Buchmeister, B. (2013). Cost-time profile simulation for job shop scheduling decisions, International Journal of Simulation Modelling, Vol. 12, No. 4, 213-224, doi:10.2507/IJSIMM12(4)1.237

[19] Jurcisin, R.; Sebo, J. (2015). Basic production scheduling concept software application in a deterministic mechanical production environment, Acta Simulatio, Vol. 1, No. 4, 1-4 